Language Teaching

http://journals.cambridge.org/LTA

Additional services for Language Teaching:

Email alerts: $\underline{\text { Click here }}$

Subscriptions: Click here

Commercial reprints: Click here

Terms of use : $\underline{\text { Click here }}$

\title{
Writing in the university: education, knowledge and reputation
}

\author{
Ken Hyland
}

Language Teaching / Volume 46 / Issue 01 / January 2013, pp 53 - 70

DOI: 10.1017/S0261444811000036, Published online: 02 March 2011

Link to this article: http://journals.cambridge.org/abstract_S0261444811000036

How to cite this article:

Ken Hyland (2013). Writing in the university: education, knowledge and reputation. Language Teaching, 46, pp 53-70 doi:10.1017/S0261444811000036

Request Permissions : $\underline{\text { Click here }}$ 


\title{
Plenary Speeches
}

\section{Writing in the university: education, knowledge and reputation}

\author{
Ken Hyland University of Hong Kong, China \\ khyland@hku.hk
}

This paper challenges the widespread view that writing is somehow peripheral to the more serious aspects of university life - doing research and teaching students. It argues that universities are ABOUT writing and that specialist forms of academic literacy are at the heart of everything we do: central to constructing knowledge, educating students and negotiating a professional academic career. Seeing literacy as embedded in the beliefs and practices of individual disciplines, instead of a generic skill that students have failed to develop at school, helps explain the difficulties both students and academics have in controlling the conventions of disciplinary discourses. Ultimately, and in an important sense, we are what we write, and we need to understand the distinctive ways our disciplines have of addressing colleagues and presenting arguments, as it is through language that academics and students conceptualise their subjects and argue their claims persuasively.

\section{Introduction}

The title of this talk has a rather daunting scope but it offers a way of organising my discussion of some key aspects of academic literacy. Essentially, I want to challenge the widespread view that writing is somehow peripheral to the more serious aspects of university life - doing research and teaching students. Instead I want to argue that universities are ABOUT writing and that specialist forms of academic literacy are at the heart of everything we do. Drawing on some of my research over the past ten years, I will explore what writing means in the academy and argue that it is central to constructing knowledge, educating students and negotiating a professional academic career. Seeing literacy as embedded in the beliefs and practices of individual disciplines, instead of a generic skill that students have failed to develop at school, helps explain the difficulties both students and academics have in controlling the conventions of disciplinary discourses. Ultimately, and in an important sense, we are what we write, and we need to understand the distinctive ways our disciplines have of addressing colleagues and presenting arguments, as it is through language that academics and students conceptualise their subjects and argue their claims persuasively.

Revised version of a plenary speech given at the Enhancing Learning Experiences in Higher Education: International Conference, University of Hong Kong, 2-3 December 2010. 


\section{Why this interest?}

Writing in the academy has assumed huge importance in recent years as countless students and academics around the world must now gain fluency in the conventions of academic writing in English to understand their disciplines, to establish their careers or to successfully navigate their learning. This is mainly the result of three major developments over the past 20 years.

First, there has been a huge expansion of higher education in many countries around the world, which has meant an increasing ethnic, class and age diversity in the student body. While some groups are still massively under-represented, the fact that almost $40 \%$ of the eligible age group now attend university in the UK, for example, means that courses are no longer dominated by white, middle-class, monolingual school leavers in full-time enrolment. This more culturally, socially and linguistically heterogeneous student population means that learners bring different identities, understandings and habits of meaning-making to their learning. This new body of students is very different from those educated in more elitist times, and tutors can no longer assume their students will bring the same understandings, skills and learning experiences that will equip them with the writing competencies they need to meet the demands of their courses.

A second reason for the interest in writing is that universities and other HE institutions around the world are increasingly becoming subjected to 'teaching quality audits' by funding bodies. This has led to universities devoting more attention to the processes of teaching and learning and more resources to the training of teaching staff. Student writing is now often a key area in continuing professional development programmes: here in Hong Kong, for instance, most universities are beginning to require new academic staff to complete a course in teaching. Similarly, in the United Kingdom, following the Dearing Committee's recommendations, writing has become central to the national framework for the training of university teaching staff.

The third reason for this interest in writing is the fact that for most academics, and many students, writing now has to be done in English. English has emerged as the international language of research and scholarship. With half the world's population predicted to be speaking the language by 2050, English seems to becoming less a language than a basic academic skill for many users around the world. Some 1.2 million students now study in English outside their home countries and international students comprise almost $50 \%$ of all postgraduates in Britain, contributing $\mathcal{E} 1.5$ billion annually to universities and $\mathcal{L}^{2} 3$ billion to the economy. There is also evidence that many doctoral students studying in overseas universities are completing their Ph.D. theses in English where they have a choice (Wilson 2002).

This also, of course, has consequences for academic publishing. More than $90 \%$ of the journal literature in some scientific domains and $70 \%$ of the 17,000 titles on the Thompson Reuter Master journal List are published in English (http://science.thomsonreuters.com/). This growth in English medium publications, moreover, is occurring not only in contexts where English is the official language but also where it is used as a foreign language, so that academics from around the world are now almost compelled to publish in English. 
Standing alongside these developments, of course, are more enduring reasons for unpacking the black box of academic discourse. Not least of these is the prestige of academic writing and its traditional role as a carrier of what counts as legitimate knowledge and as authorised ways of talking about this knowledge. I want now to look a little more closely at the consequence of these developments in the three domains of my title.

\section{Education}

Student writing is at the centre of teaching and learning in higher education. While multimedia and electronic technologies are beginning to influence learning and how we assess it, writing currently remains the way in which students both consolidate and demonstrate their understanding of their subjects. The main function of writing, however, often seems to be gate-keeping and assessment. But whatever form writing takes, and it obviously differs by genre, course and discipline, it conforms to a single, institutionalised literacy which differs dramatically from that familiar to students from their homes, schools or workplaces. Trusted ways of writing are no longer valued as legitimate for making meaning when they arrive at university because of the different practices of the academy. Many students, and particularly those who are returning to study later in life, who speak English as a second language, or who have not had a smooth uninterrupted path through the education system, often find these discourses to be alien and privileged ways of writing (Ivanič 1998; Lillis 2001).

\subsection{University writing practices}

The particular kinds of writing that hold sway in the university have emerged to represent events, ideas and observations in ways that facilitate efficient, even shorthand, communication among insiders. Essentially, the process of writing involves creating a text that we assume the reader will recognise and expect, and the process of reading involves drawing on assumptions about what the writer is trying to do. Hoey (2001) likens this to dancers following each other's steps, each building sense from a text by anticipating what the other is likely to do. But while this anticipation provides for writer-reader coordination, allowing the co-construction of coherence from a text, academic writing disrupts our everyday perceptions of the world and sets up different expectations. Effective writers craft texts in a way that insiders can see as 'doing biology' or 'doing sociology', and this both restricts how something can be said and authorises the writer as someone competent to say it. In other words, students learn what counts as good writing through an understanding of their discipline and the conventions and genres regarded as effective means of representing knowledge in that discipline.

Broadly, the social practices of the academy produce particular configurations of text which cause difficulties for many students. In everyday uses of language, for example, we tend to represent things in a certain way, so that events unfold in a time sequence and agents accomplish actions. This is a 'natural' or congruent representation (Halliday 1994) in that we tend to translate our perceptions of the physical world into the grammatical system of 
language: we call it as we see it. Academic writing, however, turns our way of expressing meanings on its head through an incongruent use of language. It treats events as existing in cause and effect networks, disguises the source of modality of statements, foregrounds events rather than actors, and engages with meanings defined by the text rather than in the physical context.

These practices often confuse newcomers and force them into roles, identities and ways of writing which run counter to their experiences and intuitions about how language is used, forcing them to represent themselves in certain ways. They require us to change our normal ways of speaking in order to fit in. Ivanič (1998), for instance, found that many of her 'mature' female students felt insecure about their educational identity, as the discourse they were expected to use seemed pretentious and false: it did not let them 'be themselves'. L2 students often experience even greater problems as they encounter writing conventions that can differ considerably from those in their first language. These frequently demand that students are more explicit about the structure and purposes of their texts, more cautious in making claims, clearer in signposting connections, and generally that they take more responsibility for coherence and clarity in their writing (Clyne 1987).

Culture, however, is an extremely controversial notion, with no single agreed definition. One version sees it as a historically transmitted and systematic network of meanings which allow us to understand, develop and communicate our knowledge and beliefs about the world (Street 1995; Lantolf 1999). Language and learning are, therefore, intrinsically bound up with culture. This is partly because our cultural values are carried through language, but also because cultures make available certain taken-for-granted ways of organising our understandings, including those we use to learn and to communicate.

\subsection{Modifying claims: Hong Kong versus United Kingdom student exams}

The trouble with such broad generalisations, however, is that it is all too easy to overemphasise differences and place the blame on culture for students' writing difficulties. For example, some years ago John Milton and I explored a corpus of 1,800 GCE A level exam papers (a high school matriculation exam) by Hong Kong (HK) and British (UK) school leavers for HEDGES and Boosters (Hyland \& Milton 1997). Essentially, these are labels given to the linguistic features we use to mitigate or tone down (hedge) our statements, or to strengthen (boost) them. In that study we found that while both groups of students used the same number of devices overall, about one in every 50 words, the UK students (almost all native speakers of English) used over a third as many hedges and the HK students almost twice as many boosters.

Figure 1 shows the percentage distributions among certainty, probability and possibility items in the texts of the two groups, with the dark bars showing the percentage of each used by HK students and the light bars the uses by UK students. We can see from this that the HK students were more likely to be definite and certain, while the UK students expressed statements more cautiously as probabilities. Both groups expressed possibility equally.

While this might seem a small point, such differences are not always viewed as merely preferred alternative ways for expressing ideas in different languages, but have pragmatic 


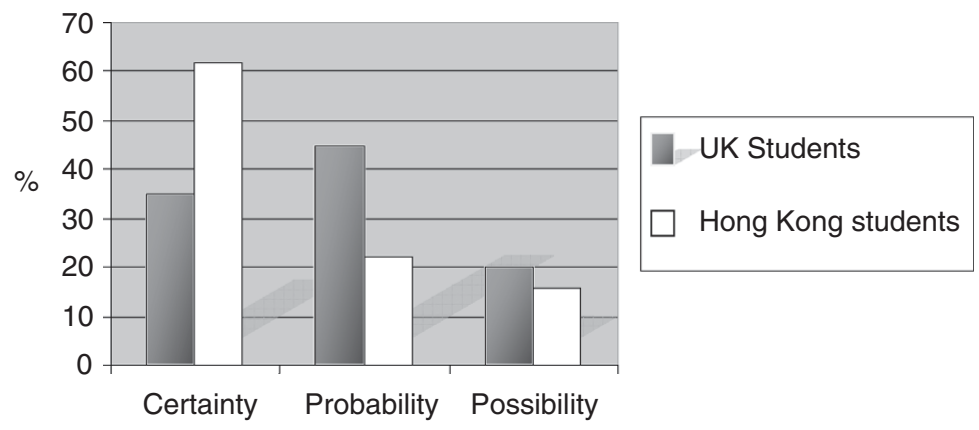

Figure 1 Hedges and boosters in A Level corpus

consequences. The fact that the HK students' writing seems much stronger can lead English speaking readers, approaching a text with another set of expectations, to make negative moral or cultural judgements about the writer. Take this example from the HK students' corpus:

(1) There is strong evidence to demonstrate the relationship between EQ and the academic performance. High EQ is definitely an advantage in any domain of life and we all know that a person with high EQ can certainly manage their own feelings well and deal effectively with others. The fact that the trend from overseas is always affecting Hong Kong people means that schools must now teach boys to be equal to female. They have their right to express emotion.

The generous peppering of boosters in this example (underlined) can make the writer appear rather too assertive, over-confident and perhaps even dogmatic. In contrast, the greater use of hedges (underlined) in the native English speaker sample below is more in line with what we expect, so we attribute positive qualities to the writer, seeing subtlety, circumspection and openness to the views of readers:

(2) Britain is probably one of the few countries in the world where the constitution is not written down. This might seem to be somewhat disorganised and although it has worked fairly well until now, I suggest that this is likely to be unrealistic for much longer and it is possible we may need a Bill of Rights as there is in the USA.

We have to be aware of the possible prejudicial effects of our unconscious expectations, but I don't believe these differences are really a result of differences in culture. On the contrary, contrastive rhetoricians, comparing writing across languages, often expect Chinese students, immersed as they are supposed to be in Buddhist conceptions of face, to be more circumspect and respectful than brash, assertive UK writers (see Hinkel 1997). In fact, proficiency seemed to play a big role in these results, with the higher grade students' uses of these forms more closely approximating the native English speaker uses. Looking more closely for reasons by means of interviews with students and studies of secondary school textbooks, we discovered that these HK writers were over-generalising what they were taught about the need to 
be direct when writing in English. The main point I want to make here, however, is that examining large numbers of instances and interviewing students can tell us a great deal about students' learning experiences, their understandings of writing, and the ways they respond to writing tasks in English.

\subsection{Seeing literacy as rules}

Overall, though, the idea that university students can't write is central to official and public debate. It forms part of the public discourse of literacy crisis, falling standards, and the collapse of Western civilisation. Unfortunately, the issue is framed in a way that makes it harder to reach a resolution. Public debate on higher education, from radio phone-in programmes in Hong Kong to the Dearing Report in the UK, assumes a model of writing which separates language, writer and context. It sees students as identical and isolated, trying to acquire a set of skills independently of their identities, purposes and disciplines.

This echoes traditional linguistic conceptions of language like Saussure's distinction between langue - or language as system - and parole - language as use. This separation of system and meaning also lies behind the familiar CONDUIT METAPHOR of language, which suggests that others are able to recover our thoughts from our words exactly as we intended: communication simply involves encoding and decoding meanings, with no differences in interpretation or reader positions. Writing is regarded as an autonomous system that we all understand and use in roughly the same way and that is transparent in reflecting meanings, as opposed to the way individuals negotiate and construct meanings. In this view, then, good writing is largely a matter of grammatical accuracy. Literacy is a set of discrete, value-free rules and technical skills, so if we can decode and encode meanings, manipulate writing tools, perceive shape-sound correspondences and so on, all will be well. In higher education this pervasive view has two main implications.

First, by divorcing language from context, academic literacy is misrepresented as a naturalised, self-evident and non-contestable way of participating in academic communities. There is a single literacy, and academic language is all the same: it's just a bit harder than the language we use at home or at school. In response, institutions have invested in language centres to provide learners with the literacy resources they need to cope at university. But these programmes tend to be voluntary rather than compulsory, general rather than specific, and isolated rather than embedded in students' learning experiences. These factors not only limit the effectiveness of such programmes, but contribute to an ideology which transforms literacy from a key area of academic practice - how we construct ourselves as credible linguists, psychologists or whatever - into a kind of add-on to the more serious activities of university life. English for Academic Purposes (EAP), the practice of academic literacy instruction, thus becomes a kind of support mechanism on the margins of academic work.

Second, if we regard academic writing as just a specific kind of top-up to the literacy skills needed in everyday life, any writing difficulties can be seen as a deficiency in the student. Weak writing skills can be attributed to laziness, inattention or poor schooling, problems which can be put right with a few English classes. This diverts attention from a critical understanding of the writing that students are asked to do in their courses, and encourages both students 
and tutors to see academic writing instruction as a grammar top-up for weak learners. EAP becomes a band-aid measure to fix deficiencies in the students themselves.

\subsection{Seeing literacies as practices}

The massive expansion of research into academic writing in recent years, however, testifies to the significance of social context and allows us to reconceptualise literacy as a social practice rather than a set of skills (Barton 1994; Anstey \& Bull 2004). The concepts of LITERACIES, referring to language use as something people DO when they interact with one another, and PRACTICES, the idea that these language activities are bound up with routine, everyday activities in the real world, provide ways of re-establishing this link between language and context. Moving away from literacy as an individual attribute is a central implication of this view. It helps us to see that words offer broad constraints on understanding but need to be, as Kress (2003: 4) puts it, 'filled in with meaning' which comes from our past experience of them. Basically, then, literacy is a resource for social groups, realised in social relationships and acting to pattern and structure those groups. Studying writing and the activities that surround it therefore become powerful tools for understanding the experiences of everyone in higher education, whether students or tutors.

First, it helps us to see that texts don't exist in isolation but are part of the communicative routines of social communities. This means not only that genres are related to other genres and the texts we read are connected to the texts we write, but that language is intimately related to the different epistemological frameworks of the disciplines and inseparable from how they understand the world. Bartholomae's famous quote captures this well:

Every time a student sits down to write for us, he has to invent the university for the occasion - invent the university, that is, or a branch of it, like history or anthropology or economics or English. The student has to learn to speak our language, to speak as we do, to try on the peculiar ways of knowing, selecting, evaluating, reporting, concluding, and arguing that define the discourse of our community. (Bartholomae 1986: 4)

Such 'ways of knowing' are not learned by rote but by writing. Teaching writing therefore needs to be embedded in subject learning to provide students with a means of conceptualising disciplinary epistemologies.

Second, this means, in turn, using the analytical tools of applied linguistics to describe the features of academic genres so we can make these explicit to students. This is the domain of EAP, which draws on applied linguistics and an eclectic theoretical base to provide grounded insights into the structures and meanings of texts, the demands placed by academic contexts on communicative behaviours, and the pedagogic practices by which those behaviours can be developed. This means going beyond the teaching of lists of supposedly common grammatical structures and vocabulary which autonomous views of literacy assume, to understanding the choices language users make to most effectively express their intended meanings. It means trying to understand the practices of real people communicating in real contexts by describing and analysing relevant texts; interpreting the processes involved in creating 
and using these texts; and exploring the connections between disciplinary writing and the institutional practices it sustains (Hyland 2003, 2006).

Third, the study of academic literacy also encourages us to look beyond the immediate context of writing to explore a wider and more abstract notion of culture: the ways that institutional and disciplinary structures impact on language use. Socially powerful institutions, such as education, support dominant literacy practices that are part of organised configurations of power and knowledge embodied in social relationships. Other vernacular literacies in people's everyday lives are less visible, less prestigious and less supported (Barton \& Hamilton 1998). In higher education, what Fairclough (1992) calls 'orders of discourse', the arrangement of discourses like seminars, lectures and essays, provide configurations of practices which govern what can be known, who can know it, and how it can be discussed.

Benesch (2001) has argued that teachers need to engage with issues of power by questioning rather than reinforcing conformity to dominant discourses. The view here is that our teaching practices should be less ACCOMMODATIONIST to dominant political and institutional orders, helping students to perform the best they can while 'encouraging them to question and shape the education they are getting' (Benesch 2001: xvii). By exploring these connections between institutions and literacy, both tutors and students are in a better position to understand and critique their disciplines and to identify the role which academic literacy plays in shaping both disciplines and individuals.

\section{Knowledge}

This brings us neatly to the second part of my talk, as we move on to KNOWLEDGE. If we reject the idea of language as a transparent medium of communication where words correspond unambiguously to meanings, then we problematise writing and the ways that academics report their claims. The fact that there are multiple interpretations of words, and numerous ways of constructing arguments, means that writing can never just simply be a way of neutrally reporting observations made in the lab or in some other research context. It foregrounds writing by giving prominence to how academics reach agreement on claims and the ways disciplines construct knowledge.

\subsection{Induction and pursuit of 'truth'}

Academic writing clearly enjoys a privileged status in the West, representing what Lemke (1995: 178) calls 'the discourse of "Truth". It is perceived as providing an objective description of what the natural and human world is actually like and this, in turn, serves to distinguish it from the socially contingent. We see this form of persuasion as a guarantee of reliable knowledge, and we invest it with cultural authority, free of the cynicism with which we view the partisan rhetoric of politics and commerce. Through induction, experimentation and falsification it gives us direct access to the external world, and the text is just a channel to report observable facts. 
But induction does not offer cast-iron proof, and by moving from observations of instances to statements about unobserved cases, we introduce uncertainty. The problem for scientific knowledge, then, is that interpretation always depends on the assumptions scientists bring to the problem. As the celebrated physicist Stephen Hawking (1993: 43) notes:

... . a theory may describe a range of observations, but beyond that it makes no sense to ask if it corresponds to reality, because we do not know what reality is independent of a theory.

In other words, there is always going to be more than one possible interpretation of data, and the fact that we can have these competing explanations shifts attention from the laboratory or clipboard to the ways that academics argue their claims. We have to look for proof in the textual practices for producing agreement. At the heart of academic persuasion is writers' attempts both to foresee and address potentially negative reactions to their claims, and to do this they use the discourses of their disciplines.

\subsection{The rhetorical construction of truth}

This social constructivist position suggests that knowledge and social reality are created through daily interactions between people, and particularly through their discourse. It rejects taken-for-granted knowledge and opposes empiricism and positivism, which have traditionally been the foundation of the natural sciences - the idea that the nature of the world can be revealed by observation. Social constructionism cautions us to be suspicious about the 'facts' of existence and encourages us to recognise that what we see as truth is actually filtered through our theories and our language. It is based on categories which are culturally and historically specific. What this means is that our knowledge of the world is not derived from observation, but constructed by people through their interactions in daily life, acting as members of social groups. Discourse is therefore at the heart of relationships, knowledge and scientific facts, as all are rhetorically constructed. The goal of academic literacy studies is therefore to discover how people use discourse to create, sustain and change these communities; how they signal their membership; how they persuade others to accept their ideas; and so on. Stubbs (1996: 21) succinctly combines these issues into a single question:

The major intellectual puzzle in the social sciences is the relation between the micro and the macro. How is it that routine everyday behaviour, from moment to moment, can create and maintain social institutions over long periods of time?

This emphasises the community-based orientation to literacy I discussed in relation to education. Just as academic literacies are not just a bolt-on to home literacies, physicists don't write like philosophers nor lawyers like linguists. Writers have to establish a professionally acceptable voice and an appropriate attitude, to both their readers and their arguments. They marshal support, express collegiality, and negotiate agreement by making linguistic choices which connect their texts with their disciplines. They have to balance the claims they make for significance and novelty in their research against the convictions and expectations of their 
readers. They must make language choices which take account of readers' likely objections, background knowledge and rhetorical expectations (Hyland 2001; 2004; 2005a). In other words, the linguistic resources we unreflectively choose when we present our arguments locate us in our disciplines: they present us as competent, credible insiders and allow us to engage with other insiders, anticipating the actual or potential voices and views of our readers. In sum, it is through language that we create a stance and align ourselves with a community.

My research into a range of academic genres over the last decade or so describes some of the ways that writers in different disciplines represent themselves, their work and their readers in very different ways. A corpus of 240 research articles of 1.5 million words, for example, shows that some $75 \%$ of all features marking author visibility, such as self-mention, personal evaluation and explicit interaction with readers, occur in the humanities and social sciences (Hyland 2005b). This shouldn't, perhaps, surprise us. After all, empiricism finds its truths by observing the world, so needs a language that represents real events without the mediation of rhetoric. This is what Foucault (1974) characterised as the neo-classical search for a univocal discourse - a one-to-one correspondence between words and categories of things, which linked the rise of science with the eighteenth-century interest in dictionaries, grammars and scientific taxonomies.

But this word-meaning correspondence is an illusion, and legal disputes over the most explicitly written legal documents show how words can have multiple meanings. Simply put, the relative impersonality of scientific discourse is not an absence of rhetoric but a different kind of rhetoric, based, like all persuasive writing, on an assumed consensus about how language can be used within particular communities. Let me illustrate this with some brief examples from my research.

\subsection{Disciplinary variation of lexical meanings}

First of all, our love affair with the idea of a single academic vocabulary seems to have worn off. In a study into an academic corpus of 3.5 million words, for example, Polly Tse and I (Hyland \& Tse 2007) found that so-called universal semi-technical items in Coxhead's Academic Word List actually have widely different frequencies and preferred meanings in different fields. For example:

- consist means 'stay the same' in social sciences and 'composed of' in the sciences.

- volume means 'book' in applied linguistics and 'quantity' in biology.

- abstract means 'remove' in engineering and 'theoretical' in social sciences.

Similarly, Ward (2009) compared lexical items in textbooks across five engineering fields and found that gas, heat and liquid occurred almost exclusively in chemical engineering. He also found items like system, time, value and factor, which were very high across all engineering fields, but they collocated very differently, giving these words different technical meanings (settling time, critical value, load factor). 


\subsection{Variation in directives}

Another feature which varies across disciplines is the use of directives. These are devices which instruct the reader to perform an action or to see things in a way determined by the writer (Hyland 2002). They are largely expressed through imperatives (e.g. consider, note, imagine) and obligation modals (such as must, should and ought). Overall, they direct readers to three main kinds of activity: textual, physical and cognitive.

- TEXTUAL ACTS direct readers to another part of the text or to another text (e.g. see Smith 1999, refer to table 2, etc.)

- PHYSICAL ACTS direct readers how to carry out some action in the real world (e.g. open the valve, heat the mixture).

- COGNITIVE ACTS instruct readers as to how to interpret an argument, explicitly positioning readers by encouraging them to note, concede or consider some argument or claim in the text.

Directives represent an explicit intervention in the text by the writer to guide readers to a preferred interpretation. This kind of explicit engagement with readers is a valuable rhetorical resource for writers in the social sciences, as they are unable to rely on the explanatory value of accepted experimental procedures, quantifiable methods or other aspects of scientific proofmaking. However, directives are a potentially risky device, as they instruct readers to act or see things in a way determined by the writer (Hyland 2002). As a result, most directives in the soft fields are textual, directing readers to a reference or table rather than telling them how they should interpret an argument. So examples like these are common in social science research articles:

see Steuer 1983 for a discussion of other contingencies' effects.

(marketing)

Look at Table 2 again for examples of behavioristic variables.

(sociology)

For transcription conventions please refer to the Appendix.

(applied linguistics)

Two of my social sciences respondents mentioned this in their interviews:

I am very conscious of using words like 'must' and 'consider' and so on and use them for a purpose. I want to say 'Right, stop here. This is important and I want you to take notice of it'. So I suppose I am trying to take control of the reader and getting them to see things my way.

(sociology interview)

I am aware of the effect that an imperative can have so I tend to use the more gentle ones. I don't want to bang them over the head with an argument I want them to reflect on what I'm saying. I use 'consider' and 'let's look at this' rather than something stronger.

(applied linguistics interview) 
In hard knowledge fields, in contrast, argument is more highly standardised and less discursive, drawing on semiotic resources which are graphical, numerical and mathematical rather than simply textual. Arguments are formulated more succinctly and papers are often less than a third the length of those in the social sciences and humanities, as both editors and scientists struggle with the continuing expansion of knowledge in the sciences. Cognitive directives are far more frequent here, as they help writers cut directly to the heart of complex arguments, explicitly positioning readers by leading them through an argument or emphasising what they should attend to:

What has to be recognised is that these issues...

(mechanical engineering)

Consider the case where a very versatile milling machine of type M5...

(electrical engineering)

A distinction must be made between cytogenetic and molecular resolution.

(biology)

My informants noted this in their interviews:

I rarely give a lot of attention to the dressing, I look for the meat - the findings - and if the argument is sound. If someone wants to save me time in getting there then that is fine. No, I'm not worried about imperatives leading me through it.

(electrical engineering interview)

I'm very conscious of how I write and I am happy to use an imperative if it puts my idea over clearly. Often we are trying to work to word limits anyway, squeezing fairly complex arguments into a tight space.

(mechanical engineering interview)

\subsection{Variation in bundles}

Finally, lexical bundles, or frequently occurring word sequences. These are a key way that particular disciplines produce community specific meanings and contribute to a sense of distinctiveness and naturalness in a register. So collocations like as a result of and it should be noted that help identify a text as belonging to an academic register, while in pursuance of, and in accordance with mark out a legal text. Their frequent use helps to identify competent language ability among individuals and to signal membership of a particular academic community. Using a corpus of 120 research articles and 120 postgraduate dissertations in four disciplines, I found that the most common bundles in this academic corpus of 3.5 million words were on the other hand, at the same time and in the case of, all of which occurred over 100 times per million words (Hyland 2008).

There are considerable disciplinary variations in the use and frequencies of different bundles, with the top 20 most common shown in Table 1 . The extent to which specific fields make use of particular strings is shown by items that occur in all four disciplines being marked 
Table 1 Most frequent four-word bundles (bold = in four disciplines; shaded = in three disciplines)

\begin{tabular}{|c|c|c|c|}
\hline Biology & Electrical engineering & Applied linguistics & Business studies \\
\hline $\begin{array}{l}\text { in the presence of } \\
\text { in the present study } \\
\text { on the other hand } \\
\text { the end of the } \\
\text { is one of the } \\
\text { at the end of } \\
\text { it was found that } \\
\text { at the beginning of } \\
\text { as well as the } \\
\text { as a result of } \\
\text { it is possible that } \\
\text { are shown in figure } \\
\text { was found to be } \\
\text { be due to the } \\
\text { in the case of } \\
\text { is shown in figure } \\
\text { the beginning of the } \\
\text { the nature of the } \\
\text { the fact that the } \\
\text { may be due to }\end{array}$ & $\begin{array}{l}\text { on the other hand } \\
\text { as shown in figure } \\
\text { in the case of } \\
\text { is shown in figure } \\
\text { it can be seen } \\
\text { as shown in fig } \\
\text { is shown in fig } \\
\text { can be seen that } \\
\text { can be used to } \\
\text { the performance of the } \\
\text { as a function of } \\
\text { is based on the } \\
\text { with respect to the } \\
\text { is given by equation } \\
\text { the effect of the } \\
\text { the magnitude of the } \\
\text { at the same time } \\
\text { in this case the } \\
\text { it is found that } \\
\text { the size of the }\end{array}$ & $\begin{array}{l}\text { on the other hand } \\
\text { at the same time } \\
\text { in terms of the } \\
\text { on the basis of } \\
\text { in relation to the } \\
\text { in the case of } \\
\text { in the present study } \\
\text { the end of the } \\
\text { the nature of the } \\
\text { in the form of } \\
\text { as well as the } \\
\text { at the end of } \\
\text { the fact that the } \\
\text { in the context of } \\
\text { is one of the } \\
\text { in the process of } \\
\text { the results of the } \\
\text { in terms of their } \\
\text { to the fact that } \\
\text { in the sense that }\end{array}$ & $\begin{array}{l}\text { on the other hand } \\
\text { in the case of } \\
\text { at the same time } \\
\text { at the end of } \\
\text { on the basis of } \\
\text { as well as the } \\
\text { the extent to which } \\
\text { the end of the } \\
\text { significantly different from zero } \\
\text { are more likely to } \\
\text { the relationship between the } \\
\text { the results of the } \\
\text { the Hang Seng index } \\
\text { the other hand the } \\
\text { in the context of } \\
\text { as a result of } \\
\text { the performance of the } \\
\text { Hong Kong stock market } \\
\text { is positively related to } \\
\text { are significantly different from }\end{array}$ \\
\hline
\end{tabular}

in bold and those in three disciplines shaded (Hyland 2008). Just two forms occur in all four disciplines (on the other hand and in the case of) and a handful in three fields. In fact, it turns out that over half of all items in the top 50 bundles in each discipline don't occur in the top 50 of any of the other disciplines studied here. Predictably, perhaps, we find the greatest similarities between cognate fields, so that business studies and applied linguistics share 18 items in the top 50 with on the basis of, in the context of, the relationship between the, and it is important to exclusive to these two fields. Similarly, biology and electrical engineering have 16 bundles in common, with it was found that, is shown in figure, as shown in figure, is due to the, and the presence of the not in the social science lists at all.

The electrical engineering texts contained the greatest range of high frequency bundles with 213 different four-word strings, and also the highest proportion of words in the texts occurring in four-word bundles. Biology, on the other hand, had the smallest range of bundles, the fewest examples, and the lowest proportion of texts consisting of words in bundles. Thus, the electrical engineering texts were most dependent on such common prefabricated bundles as 'it can be seen' and 'as shown in figure', and used many sequences not found in the other disciplines, perhaps because technical communication is relatively abstract and graphical. This supports analyses in systemic functional linguistics which suggest that language in science continually constructs conceptual objects that are arrayed in various syntactic relations of coexistence and causality (Halliday \& Martin 1993). Arguments might therefore function by 
Table 2 Distribution of functions of four-word bundles

\begin{tabular}{lllcc}
\hline \hline Discipline & Research-oriented & Text-oriented & Participant-oriented & Totals \\
\hline Biology & 48.1 & 43.5 & 8.4 & 100 \\
Electrical engineering & 50.4 & 40.4 & 9.2 & 100 \\
Applied linguistics & 31.3 & 49.8 & 18.9 & 100 \\
Business studies & 35.0 & 48.4 & 16.6 & 100 \\
Overall & $\mathbf{4 1 . 2}$ & $\mathbf{4 5 . 5}$ & $\mathbf{1 3 . 2}$ & $\mathbf{1 0 0}$ \\
\hline \hline
\end{tabular}

linking data or findings in routinely patterned, formulaic ways with the same forms used repeatedly.

The functions of these sequences also reveal disciplinary specificity, with a broad split across the hard and soft fields. Table 2 shows that RESEARCH-ORIENTED BUNDLES, which refer to real world activities, make up about half of all bundles in the sciences and TEXT-ORIENTED BUNDLES, which focus on argument, make up half those in the social sciences. PARTICIPANTORIENTED BUNDLES, which focus on the writer or reader of the text, provide a structure for interpreting a following proposition, conveying the writer's individual stance and personal engagement with readers, and these are twice as common in the more discursive social science fields.

Once again, these uses reflect the argument patterns in the two domains. So we can see how text-oriented examples function to connect aspects of argument (a) while those in the sciences point to research and findings (b):

(a) The term 'linguistics' might be too narrow in terms of the diverse knowledge-base and expertise that is required.

(applied linguistics) The purpose of this paper is to investigate the perceptions of consumers in the Hong Kong market toward fast food.

(business studies)

(b) The structure of the coasting-point model can be divided into three areas.

(electrical engineering)

The DNA was precipitated in the presence of 2.5 volumes of ethanol and 0.1 volume of $3.0 \mathrm{M}$ sodium acetate $\mathrm{pH}$.

(biology)

The relatively substantial presence of these items in the hard sciences reflects the fact that these disciplines place considerable emphasis on precision, particularly to ensure the accurate understanding of procedures and results. In contrast, the text-oriented strings which were particularly marked in the soft fields reflects a more discursive and evaluative pattern of argument, where persuasion is more explicitly interpretative and less empirical.

\section{Reputation}

Glearly, writing has enormous relevance to the ways individuals construct themselves as competent academics, build professional visibility and establish reputations. I've mentioned 
the importance of disciplinary discourse conventions and the need for writers to project an appropriate, community-defined stance and to engage with their readers in ways they are likely to find familiar and persuasive. In this sense the importance of academic literacy to academics cannot be overestimated. But writing has become even more important as the institutionalised system which both creates knowledge and distributes rewards: the system of publication. The system of institutional incentive, in fact, has transformed academic endeavour into a machine for the manufacture of papers. Researchers find that their work has little value for them or their university without publication. A paper is judged as a contribution to the disciplinary literature if colleagues can find it and make use of it. If editors, referees, proposal readers, conference attendees or journal readers regard a submission as original and significant, if it is published in prestigious places, and if it is cited and taken up by others in future papers, then the writer receives the reward of recognition.

\subsection{Recognition and influence}

Recognition is not simply an intangible benefit to the holder: it brings the reward of influence and the ability to wield influence in their field. Academics who excel in publishing their research achieve promotion, tenure and access to senior administrative and gate-keeping roles from which they can oversee research agendas, appointments, funding and project applications. They therefore form an elite which exercises influence in setting standards, directing strategies and determining what is considered good work or an important topic. They may also gain greater influence as spokespeople for their colleagues, both in the media and as members of government committees, thereby helping to shape perceptions of their field and the direction it moves in. This prestige and recognition is what Bourdieu (1991) refers to as symbolic capital, which bestows power on the holder. Latour \& Woolgar (1979) express this using a market metaphor, which sees academics as engaged in a cycle of activity which involves them in converting different kinds of 'credit' to enhance their credibility. Thus, a series of successful publications bestows credit on researchers, which they may be able to convert into a research grant to finance equipment and attract colleagues to conduct further research. This, in turn, will produce more data which can be converted to arguments, new publications, and so on through another cycle. Credibility thus helps academics to progress along an upward mobility path in their careers. Latour \& Woolgar put it like this:

For example, a successful investment might mean that people phone him, his abstracts are accepted, others show interest in his work, he is believed more easily and listened to with greater attention, he is offered better positions, his assays work well, data flow more reliably and form a more credible picture. (Latour \& Woolgar 1979: 204)

Success is seen as largely measured by recognition and, in turn, the process of acquiring recognition as dependent on the capacity to write papers valued by one's colleagues. 


\subsection{Publishing and competition}

Academics are, of course, motivated by curiosity and driven by a need to understand the issues they research, although most admit that recognition is an important source of professional reward, so they publish in order to further their careers. But because reputation is translated into concrete consequences, and because both material and symbolic capital are scarce, academic publication is fiercely competitive. This institutionally sanctioned competition is generally supposed to be a spur to advancing knowledge, but it is now inseparable from the process by which prestige and credibility are assessed. Publication comes to equal 'productivity' and is used as a crude measure of worth, with institutions conferring promotion and tenure on the length of personal bibliographies. The emergence of Research Assessment Exercises and publication of university league tables in many countries act to fan these flames.

Writing is both the stick and the carrot that propel us on the academic treadmill. As James Watson, Nobel laureate and a member of the biology establishment, spells out:

It starts at the beginning. If you publish first, you become a professor first; your future depends on some indication that you can do something by yourself. It's that simple. Competitiveness is very dominant. The chief emotion in the field. (Cited in Judson 1995: 194).

Competition is increasingly important with the growth of commercial incentives which, in technological fields in particular, may be even stronger than intellectual ones.

So the pressure has been increased on academics - not only is the need to publish greater than ever, but publication must be in English. Research shows that academics all over the world are increasingly less likely to publish in their own languages and find their English language publications cited more often. There were over 1.1 million peer-reviewed research articles published globally in English in 2005; this number has been increasing by $4 \%$ annually, despite falling library budgets. This has meant that the numbers of non-native English speaking academics publishing in English language journals is increasing dramatically.

References to English language publications, for example, have reached $85 \%$ in French science journals, and English makes up over 95\% of all publications in the Science Citation Index. There were, in addition, over 4,000 papers in English language social science journals in 2005, compared with only 400 just eight years earlier. With publishers increasingly encouraging libraries to subscribe to online versions of journals, the impact of English becomes selfperpetuating, since it is in these journals where authors will be most visible on the world stage and receive the most credit. Many European and Japanese journals, for instance, have switched to English, journals in Swedish, Dutch and German being extremely hard hit.

Clearly a lingua franca facilitates the exchange of ideas far more effectively than a polyglot system, but there is a real danger this will exclude many L2 writers from the web of global scholarship, so depriving the world of knowledge developed outside the Anglophone centres of research. One consequence has been the development of 'writing for publication' courses for academic staff at universities around the world. In Hong Kong, staff were extremely appreciative of these courses, but also very secretive about actually attending them. This is perhaps another feature of academic writing that I haven't mentioned: not only does it have to be engaging, interesting and persuasive, it must also be effortless. 


\section{Conclusions}

It might seem that as an applied linguist I've attached too much importance to the object of my trade and been guilty of over-emphasising the impact of writing in the academy. After all, being a successful student, publishing academic, influential researcher or whatever involves other competencies - craft skills, wide reading, analytical and critical abilities and so on. But while diligence and brilliance will get you a long way, we are ultimately defined and judged by our writing. It is important to stress that this writing isn't just an abstract skill, but a core aspect of the epistemological frameworks of our fields and of our identities as academics. We are what we write, and we need to understand the distinctive ways our disciplines have of identifying issues, asking questions, addressing a literature, criticising colleagues and presenting arguments.

To sum up: knowledge, disciplines and the professional careers of academics themselves are ultimately constructed through the ways we write. What I have been arguing is that we need to understand the full complexity of writing as a situated activity and to recognise its central place in our practices. To do this is to both improve our practice and ensure that the teaching of academic discourse is not artificially divorced from the teaching of academic subjects.

\section{References}

Anstey, M. \& G. Bull (2004). Literacy as social practice: The literacy labyrinth (2nd edn). Sydney: Pearson. Bartholomae, D. (1986). Inventing the university. Fournal of Basic Writing 5, 4-23.

Barton, D (1994). The social basis of literacy: An introduction to the ecology of written language. Oxford: Blackwell. Barton, D. \& M. Hamilton (1998). Local literacies. London: Routledge.

Benesch, S. (2001). Critical English for academic purposes. Mahwah NJ: Lawrence Erlbaum.

Bourdieu, P. (1991). Language and symbolic power. Oxford: Polity Press.

Clyne, M. (1987). Cultural differences in the organisation of academic texts. Fournal of Pragmatics 11, 211-247.

Fairclough, N. (1992). Discourse and social change. Cambridge: Polity Press.

Foucault, M. (1974). The order of things. London: Tavistock Press.

Halliday, M. A. K. (1994). An introduction to Functional Grammar (2nd edn). London: Edward Arnold.

Halliday, M. \& J. Martin (1993). Writing science. Literacy and discursive power. London: Falmer Press.

Hawking, S. (1993). Black holes and baby universes and other essays. New York: Bantam Books.

Hinkel, E. (1997). Indirectness in L1 and L2 academic writing. Journal of Pragmatics 27.3, 360-386.

Hoey, M. (2001). Textual interaction: An introduction to written text analysis. London: Routledge.

Hyland, K. (2001). Bringing in the reader: Addressee features in academic articles. Written Communication $18.4,549-574$.

Hyland, K. (2002). Directives: Argument and engagement in academic writing. Applied Linguistics 23.2, 215-239.

Hyland, K. (2003). Second language writing. New York: CUP.

Hyland, K. (2004). Disciplinary discourses: Social interactions in academic writing. Ann Arbor MI: University of Michigan Press.

Hyland, K. (2005a). Metadiscourse: Interactions in writing. London: Continuum.

Hyland, K. (2005b). Stance and engagement: A model of interaction in academic discourse. Discourse Studies 7.2, 173-191.

Hyland, K. (2006). English for academic purposes. London: Routledge.

Hyland, K. (2008). As can be seen: Lexical bundles and disciplinary variation. English for Specific Purposes $27.1,4-21$. 
Hyland, K. \& J. Milton (1997). Qualification and certainty in L1 and L2 students' writing. Fournal of Second Language Writing 16.2, 183-205.

Hyland, K. \& P. Tse (2007). 'Is there an "academic vocabulary”?' TESOL Quarterly 41.2, 235-254.

Ivanič, R. (1998). Writing and identity: The discoursal construction of identity in academic writing. Amsterdam: Benjamins.

Judson, H. (1995). The eighth day of creation: The makers of the revolution in biology. Harmondsworth: Penguin Books.

Kress, G. (2003). Literacy in the new media age. London: Routledge.

Lantolf, J. P. (1999). Second culture acquisition: Cognitive considerations. In E. Hinkel (ed.), Culture in second language teaching and learning. Cambridge: Cambridge University Press, 28-46.

Latour, B. \& S. Woolgar (1979). Laboratory life: The social construction of scientific facts. Beverly Hills: Sage.

Lemke, J. (1995). Textual politics: discourse and social dynamics. London: Taylor and Francis.

Lillis, T. (2001). Student writing: Access, regulation, desire. London: Routledge.

Street, B. (1995). Social literacies. London: Longman.

Stubbs, M. (1996). Text and corpus analysis. Oxford: Blackwell.

Ward, J. (2009). EAP reading and lexis for Thai engineering undergraduates. Fournal of English for Academic Purposes 8.4, 294-301.

Wilson, D. (2002). The Englishization of academe: A Finnish perspective. Jyväskylä, Finland: University of Jyväskylä Language Centre.

Ken Hyland is Professor of Applied Linguistics and Director of the Centre for Applied English Studies at the University of Hong Kong. He has published over 150 articles and 14 books on language education and academic writing and is currently completing a book on disciplinary identity. He was founding co-editor of the Fournal of English for Academic Purposes and is now co-editor of Applied Linguistics. 